\title{
SEXUALIDADE E EDUCAÇÃO SEXUAL: UMA PERSPECTIVA INTERDISCIPLINAR NA EDUCAÇÃO INFANTIL
}

SEXUALIDAD Y EDUCACIÓN SEXUAL: UNA PERSPECTIVA INTERDICIPLINAR EN LA EDUCACIÓN INFANTIL

\section{SEXUALITY AND SEXUAL EDUCATION: AN INTERDISCIPLINARY PERSPECTIVE IN CHILDHOOD EDUCATION}

Maria Fernanda Celli de OLIVEIRA Universidade Estadual Paulista (UNESP), Araraquara - SP - Brasil. Doutoranda do Programa de Pós-Graduação em Educação Escolar. ORCID: https://orcid.org/0000-0001-6358-7986.

E-mail: maria.c.oliveira@unesp.br

\section{Luci Regina MUZZETI}

Universidade Estadual Paulista (UNESP), Araraquara - SP - Brasil. Professora Titular do Departamento de Didática. Doutorado em Educação (UFSCAR). ORCID: https://orcid.org/0000-0002-6808-2490.

E-mail: luci.muzzeti@unesp.br

\section{Laís Inês Sanseverinato MICHELETI}

Universidade Estadual Paulista (UNESP), Araraquara - SP - Brasil. Mestranda do Programa de Pós-Graduação em Educação Escolar. ORCID: https://orcid.org/0000-0002-2748-3407.

E-mail: lais.ines@ outlookl.com 
OLIVEIRA, M. F. C.; MUZZETI, L. R.; MICHELETI, L. I. S. Sexualidade e educação sexual: uma perspectiva interdisciplinar na educação infantil . R. Científica UBM - Barra Mansa (RJ), ano XXVI,v. 23, n. 44,

1. Sem. 2021 p.90-102.

ISSN 1516-4071

Aprovado em: 15/11/2020

\section{RESUMO}

As temáticas relacionadas à sexualidade nem sempre são vistas como um conteúdo interdisciplinar e, tratar do tema dentro ou fora da instituição de ensino ainda é um tabu que necessita ser desmistificado e incorporado ao saber científico e social. Nesse sentido, o objetivo deste trabalho é trazer alguns apontamentos acerca da possibilidade de interdisciplinaridade no âmbito escolar, acerca da sexualidade e educação sexual na educação infantil. A partir dessa ideia, buscou - se, com este artigo, levantar algumas discussões sobre a problemática e, sobretudo, quais as contribuições que estas pode trazer à sociedade em geral, especialmente às crianças atendidas pelo sistema brasileiro de ensino.

Palavras-Chave: Educação sexual. Educação infantil. Escola. Interdisciplinaridade. Sexualidade.

\section{RESUMEN}

Las temáticas relacionadas a la sexualidad ni siempre son vistas como un contenido interdisciplinar y tratar del tema dentro y fuera de la institución de enseñanza aunque es un tabú que necesita ser desmitificado e incorporado al saber científico y social. En este sentido, el objetivo de este trabajo es traer algunos apuntamientos acerca de la posibilidad de interdisciplinaridad en el ámbito escolar, acerca de la sexualidad y educación sexual en la educación infantil. A partir de esta idea, buscó-se con este artículo, levantar algunas discusiones sobre la problemática y sobretodo, cuáles las contribuciones que esta puede traer a la sociedad en general, especialmente a los niños atendidos por el sistema brasileño de enseñanza.

Palabras Clave: Educación escolar. Educación infantil. Escuela. Interdisciplinaridad. Sexualidad.

\section{ABSTRACT}

The themes related to sexuality are not always seen as an interdisciplinary content and, dealing with the topic inside or outside the educational institution is still a taboo that needs to be demystified and incorporated into scientific and social knowledge. In this sense, the objective of this work is to bring some notes about the possibility of interdisciplinarity in the school context, about sexuality and sexual education in early childhood education. Based on this idea, this article sought to raise some discussions about the problem and, above all, what contributions it can bring to society in general, especially to the children served by the Brazilian education system.

Keywords: Educação sexual. Educação infantil. Escola. Interdisciplinaridade. Sexualidade. 
OLIVEIRA, M. F. C.; MUZZETI, L. R.; MICHELETI, L. I. S. Sexualidade e educação sexual: uma perspectiva interdisciplinar na educação infantil . R. Científica UBM - Barra Mansa (RJ), ano XXVI,v. 23, n. 44, 1 .

Sem. 2021 p.90-102.

ISSN 1516-4071

\section{INTRODUÇÃO}

As diversas transformações que a sociedade passou ao longo do tempo modificaram, dentre inúmeras vertentes, a maneira como a criança era vista. Os movimentos sociais que trouxeram como resultado a concepção de infância que temos hoje, implicaram também, mudanças tocantes à educação das crianças. Conforme Formigoni (2010, p. 139),

\footnotetext{
Na sociedade medieval, a criança representa um papel social mínimo, chegando a ser consideradas ao nível dos animais, pois a mortalidade infantil era elevada e isso desfavorecia a relação de afeto entre crianças e adultos.
}

Nesse sentido, podemos depreender a condição de desvalorização a qual a criança era submetida mediante a sociedade da Idade Média, o que difere consideravelmente da concepção de cuidado, zelo e afeto dedicados às crianças atualmente. A partir da dinâmica social e da mudança relacionada à estruturação da família do início da Idade Moderna, a criança ganha cada vez mais espaço no seio familiar.

Segundo Formigoni (2010), devido aos processos civilizatórios imprescindíveis a sociedade moderna e, tendo como instituição central o Estado, outras instituições foram criadas, a fim de estabelecer a ordem, bem como a disciplina, visando à ampliação do controle social. Assim,

\footnotetext{
Em particular temos a escola e a família como instituições fundamentais encarregadas em formar e cuidar dos indivíduos, não apenas de seu crescimento evolutivo e de sua instrução formal, como também de sua formação pessoal e social, em especial durante a infância e a adolescência (FORMIGONI, 2010, p. 140).
}

A partir do século XV, com base no declínio relacionado ao compromisso de viver com base na ancestralidade, a família passa a se tornar mais nuclear, valorizando e a individualidade, o que interferiu diretamente na maneira de se relacionar com as crianças.

No decorrer dos séculos XV e XVI, por meio da ascensão do Renascimento na Europa, diversos impactos acometeram o cenário mundial, também no que tange à Educação Infantil. A criança, antes considerada como um adulto em miniatura, passa a ser vista como um ser com necessidades e requerem cuidados e especificações próprias à faixa etária.

Tanto creches como pré-escolas são frutos da Revolução Industrial, quando as mães que deixavam seus lares em busca de trabalho começaram a reivindicar por lugares onde pudessem deixar seus filhos sob os olhares de cuidadores. Vale ressaltar que a preocupação relacionada especificamente à educação dos filhos(as) não era o enfoque principal dessas reivindicações, 
OLIVEIRA, M. F. C.; MUZZETI, L. R.; MICHELETI, L. I. S. Sexualidade e educação sexual: uma perspectiva interdisciplinar na educação infantil . R. Científica UBM - Barra Mansa (RJ), ano XXVI,v. 23, n. 44,

1. Sem. 2021 p.90-102.

ISSN 1516-4071

mas sim, a ânsia pelo assistencialismo, uma vez que, muitos eram demasiadamente pequenos, dependendo assim, de cuidados constante.

\begin{abstract}
A opção brasileira pelo atendimento educacional a toda a faixa etária da primeira infância e a inserção das crianças de 6 anos no ensino fundamental são frutos de um processo histórico de articulação entre duas dimensões: uma social, política e administrativa - que foi se expressando ao longo dos últimos cem anos com os movimentos sociais e de lutas de diferentes setores da sociedade civil organizada - e outra técnico-científica, constituída por estudos da psicologia, antropologia, filosofia, sociologia, entre outros, que passam a conceber a criança de forma ampla e integrada, e a infância como um momento fundamental no processo de formação humana (KRAMER; NUNES; CORSINO, 2011, p. 71).
\end{abstract}

Foi só a partir da década de 1980 que emergiu a preocupação em oferecer uma formação adequada para o desenvolvimento integral da criança acompanhando os ideais escolanovistas, agora mais fortemente presentes no país. Para tanto, estudos surgiram com o intuito de afirmar que, independentemente da camada social, essa fase da educação era imprescindível e deveria ser acessível a toda a população, sem exceções quanto a classes sociais. Nesse momento, então, surgem as primeiras escolas de Educação Infantil que, a princípio, tiveram um papel assistencialista, ou seja, de 'cuidadoras'.

Em 1988, a Constituição (BRASIL, 1988) reconhece e define a Educação Infantil como um direito da família e dever do Estado, sendo reafirmado posteriormente, no ano de 1990, pelo ECA - Estatuto da Criança e do Adolescente (BRASIL, 1990). Já no ano de 1994, o MEC publica um documento (BRASIL, 1994) que amplia as vagas nas unidades de Educação Infantil a fim de garantir o direito de acesso a todas as crianças, além de sinalizar a importância da formação profissional das educadoras que atuam com essa faixa etária. Porém, a LDB - Lei ${ }^{\circ}$ 9.394/96 - Lei de Diretrizes e Bases Curriculares Nacionais (BRASIL, 1996) fora promulgada dois anos mais tarde, em 1996, em que a importância da Educação Infantil foi oficializada, passando a ser a primeira etapa da Educação Básica.

Com a LDB (BRASIL, 1996), finalmente fora reconhecido que a Educação Infantil era imprescindível, sendo um momento determinante e essencial na formação e desenvolvimento das crianças. Dessa forma, foi recomendado que todas os profissionais que atuassem com essa faixa etária também deveriam adequar sua formação profissional, devendo cursar o Ensino Superior, ou seja, deveriam ser graduadas.

Todavia, mesmo depois de 20 anos, o direito das crianças de receber uma educação de qualidade e efetiva ainda tende a não se fazer presente em diversas instituições de ensino. Várias destas expõem seus alunos a profissionais não qualificadas e sem formação docente, desvalorizando e boicotando assim, a importância da profissional da Educação Infantil, 
OLIVEIRA, M. F. C.; MUZZETI, L. R.; MICHELETI, L. I. S. Sexualidade e educação sexual: uma perspectiva interdisciplinar na educação infantil . R. Científica UBM - Barra Mansa (RJ), ano XXVI,v. 23, n. 44, 1 .

deixando as crianças atendidas por essas instituições à margem da sociedade, uma vez que o caráter assistencialista destas já havia sido teoricamente descaracterizado e superado, conforme garantido pela Constituição.

Alguns estudos como de Leôncio (2013), demonstram que há uma ausência de qualificação profissional e a falta de capacitação de muitos outros contribuem para diversas lacunas no processo de desenvolvimento da criança da Educação Infantil, inclusive no que diz respeito à formação moral, social e psicológica dos agentes atendidos, inclusive no tocante as temáticas relacionadas à educação sexual.

As questões relacionadas ao gênero, por exemplo, tendem a não serem vistas como fator de formação pessoal mesmo atualmente, após décadas de lutas e avanços relacionados à sexualidade. Conforme Guizzo e Felipe (2015) o ensino de Educação Sexual nas escolas nunca fora um assunto a ser discutido dentro e/ou fora dela. Os tabus e preconceitos estabelecidos histórico e culturalmente criaram uma barreira em relação ao assunto, e, mesmo na atualidade, tratar tais temáticas pode ser um símbolo de muitas dificuldades ligadas à repressão, machismo e incontáveis equívocos, tornando-se por vezes, uma violência simbólica.

\section{DESENVOLVIMENTO}

\subsection{O PERCURSO DA SEXUALIDADE NO BRASIL}

Conforme Ribeiro (2009) a transição do século XIX para o século XX fora marcada por diversas lutas ligadas à sexualidade, que vão desde o combate à sífilis e as mais variadas doenças venéreas, até o advento da pílula anticoncepcional, movimentos pró-sexualidade (hippie, por exemplo) e a disseminação da AIDS nos anos 80. Porém, mesmo tantas décadas depois, os assuntos que dizem respeito à sexualidade humana ainda são tratados como algo distante e mostra-se como um fator de incômodo nas discussões sociais.

Segundo Guizzo e Felipe (2015), a partir da segunda metade do século XX, alguns grupos que permaneceram por muitos anos à margem da sociedade, começaram a reivindicar seus direitos e questionar, assim, a educação no Brasil. "Tais segmentos, a saber: indígenas, portadores de necessidades especiais, negros/as, mulheres e não heterossexuais, (GUIZZO; FELIPE, 2015, p. 2)" clamavam por uma identidade própria que considerasse as diferenças no saber, pensar e agir. Esses movimentos foram ganhando força, especialmente após a década de 1960, com a revolução sexual. 
OLIVEIRA, M. F. C.; MUZZETI, L. R.; MICHELETI, L. I. S. Sexualidade e educação sexual: uma perspectiva interdisciplinar na educação infantil . R. Científica UBM - Barra Mansa (RJ), ano XXVI,v. 23, n. 44,

1. Sem. 2021 p.90-102.

ISSN 1516-4071

No Brasil, a década de 1990 foi marcada por um contexto reivindicatório em que diferentes movimentos sociais denunciaram as práticas discriminatórias presentes na educação e exigiram mudanças. O Ministério da Educação tem promovido iniciativas, debates e discussões com o propósito de superar os preconceitos e as discriminações em instituições escolares em função de especificidades que marcam os sujeitos como "diferentes". Estas discussões, bem como outras ações de movimentos sociais, contribuíram para a elaboração de documentos oficiais que teriam emergido com o propósito de proporcionar uma educação similar para todos e todas independente de gênero, raça, sexualidade, classe social e outros marcadores possíveis (GUIZZO; FELIPE, 2015, p. 3).

Assim, com base na preocupação de formar adultos conscientes e capazes de compreender a natureza das relações humanas, bem como as diferenças e peculiaridades, sobretudo, naquilo que diz respeito à sexualidade, o Ministério da Educação (BRASIL, 1997) sugere que a Educação Sexual deve estar presente no currículo das escolas desde cedo, como um tema transversal, ou seja, não se tratando de uma disciplina obrigatória e fixa da grade curricular, mas devendo estar atrelada a outras matérias, comumente abordada na biologia.

Tal sugestão está descrita nos PCNs, os Parâmetros Curriculares Nacionais (BRASIL, 1997), documento responsável pela adequação e equação do ensino no Brasil. Por outro lado, esse documento é uma sugestão do governo, e, portanto, a não obrigatoriedade do ensino de tal temática demonstra o preconceito que ainda é fortemente enraizado e presente na cultura brasileira. Ademais, vale ressaltar que os PCNs foram o primeiro reconhecimento de porte Nacional, que legitimou a necessidade e importância da implantação de programas de orientação de Educação Sexual nas escolas que atendem crianças e adolescentes, o que não abrange, porém, a Educação Infantil, perpetuando assim, a ideia de falta de necessidade da abordagem na referida faixa etária.

De qualquer maneira, a educação sexual deve ser promovida em todos os âmbitos e dentre todas as faixas etária, considerando as diferenças culturais, uma vez que,

\footnotetext{
As necessidades e preocupações da saúde sexual e reprodutiva de crianças e jovens variam muito intra e inter-regiões, comunidades e países, o que pode afetar a percepção de um objetivo específico de aprendizagem. Esses objetivos devem, portanto, ser sempre ajustados ao contexto com base em dados e informações confirmadas disponíveis. De qualquer modo, a maior parte dos peritos acredita que crianças e jovens querem e precisam de informação sobre sexualidade e saúde sexual de modo abrangente e tão cedo quanto possível (UNESCO, 2013, p. 15).
}

Seguindo esta linha de pensamento, em busca da ascensão e disseminação da educação sexual dentro do âmbito escolar, propõe-se que a orientação sexual seja tratada, dentro da escola, de maneira interdisciplinar, garantindo assim, que o assunto seja encarado de maneira naturalizada e essencialmente importante para compreender o comportamento e desenvolvimento humano, em todas as suas fases. 
OLIVEIRA, M. F. C.; MUZZETI, L. R.; MICHELETI, L. I. S. Sexualidade e educação sexual: uma perspectiva interdisciplinar na educação infantil . R. Científica UBM - Barra Mansa (RJ), ano XXVI,v. 23, n. 44, 1 .

Nesse sentido, vale ressaltar que,

\begin{abstract}
O trabalho com a sexualidade com as crianças não significa distanciar-se dos fundamentos pedagógicos, os quais devem ser considerados no campo educacional. Ao contrário, faz-se mister utilizá-los para fundamentar a discussão com as crianças sem "achismos" e preconceitos, apresentando-lhes informações coerentes e de modo adequado (MONTEIRO; STORTO, 2019, p. 242).
\end{abstract}

Mas como inculcar e conscientizar a sociedade acerca da importância de tratar a Educação sexual dentro das escolas sem que esta se torne um problema? assim, propõe-se neste estudo uma discussão sobre a abordagem da temática através da interdisciplinaridade. Isso quer dizer que o tema deve passar e caminhar dentre todas as vertentes no sistema de ensino desde a mais tenra idade, de acordo com cada faixa etária, falando a linguagem de seus interlocutores e considerando a importância de viver a sexualidade, uma vez que, "em poucas palavras, a proposta da educação sexual deve conter liberdade, responsabilidade e compromisso [...]" (SAITO; LEAL, 2000, p. 46).

A sexualidade é intrínseca ao ser humano e direito de todos, conforme enfatizado pela UNESCO nas "Orientações técnicas de educação em sexualidade para o cenário brasileiro: tópicos e objetivos de aprendizagem" (UNESCO, 2013). Quando orientamos uma criança em relação à sexualidade, não apenas estamos contribuindo para a promoção de uma melhor qualidade de vida, mas também, protegemos a infância e os direitos dos pequenos, além de promover o respeito e a igualdade. Vale ressaltar que, o material destina-se a crianças a partir dos 5 anos de idade, o que ilustra uma das discussões do estudo aqui proposto, cujo objetivo é alertar para a despreocupação em relação a orientação sexual das crianças menores. Ora, se a sexualidade é algo inerente ao ser humano, por que não há maiores preocupações com a orientação das crianças desde a mais tenra idade?

Como dito anteriormente, a educação infantil, apesar de seus avanços, ainda demonstrase de maneira recorrente como uma fase desvalorizada, tendo sua importância contraditoriamente negada, e, por vezes, desconsiderada em relação ao desenvolvimento integral da criança. Logo, o documento discorre que "Educadores e educadoras da Educação Infantil e, eventualmente, de outros níveis, devem avaliar a adequação dos conteúdos dos tópicos a crianças de faixas etárias anteriores" (UNESCO, 2013, p. 17). 
OLIVEIRA, M. F. C.; MUZZETI, L. R.; MICHELETI, L. I. S. Sexualidade e educação sexual: uma perspectiva interdisciplinar na educação infantil . R. Científica UBM - Barra Mansa (RJ), ano XXVI,v. 23, n. 44,

1. Sem. 2021 p.90-102.

ISSN 1516-4071

\title{
2.2 ESCOLA: SISTEMA DE REPRODUÇÃO SOCIAL
}

A sexualidade e a educação sexual devem ser promovidas dentro e fora do âmbito escolar. Fora da instituição de ensino, cabe à sociedade considerar a importância que tal temática tem para o desenvolvimento integral de todos, para assim, superar preconceitos e equívocos ainda tão presentes na atualidade. Dentro da escola, as singularidades e necessidades de todos os alunos devem ser consideradas, superando a interferência da dominação das classes sociais mais abastadas, nos conteúdos e práticas escolares tradicionais. Segundo Ortiz (1983), Bourdieu nos mostra que as classes dominantes são capazes de impor à escola as formas de avaliação e ensino que devem ser priorizadas e valorizadas na aprendizagem. Dessa forma, a escola, por meio de repreensões, advertências e conselhos, valoriza de modo implícito a cultura das frações de classes privilegiadas que tendem a ser a dos grupos sociais dominantes, exigindo dos diferentes estudantes os mesmos resultados escolares e as mesmas relações com a cultura escolar.

\begin{abstract}
A análise de Bourdieu tende, assim, a enfatizar a importância de se estudar o modo de estruturação do habitus através das instituições de socialização dos agentes. Uma vez que se considera a socialização como um processo que se desenvolve ao longo de uma série de produções de habitus distintos, dedica-se uma atenção particular ao período de formação das primeiras categorias e valores que orientam a prática futura do ator (o que aproxima Bourdieu da escola fenomenológica que privilegia a experiência primeira do sujeito). A ação pedagógica na primeira fase de formação do agente é vista como produtora de um 'hábito primário, característica de um grupo ou de uma classe que está no princípio da constituição ulterior de todo outro hábito'. As estruturas de um habitus logicamente anteriores comandam, portanto, o processo de estruturação de novos habitus a serem produzidos por novas agências pedagógicas (ORTIZ, 1983, p. 18).
\end{abstract}

Com isso, não se levam em conta as culturas dos diferentes educandos, oriundos de meios culturais e econômicos diversos. Entende-se que, quanto mais a herança familiar se afasta da cultura dominante, mais desvalorizada esta será pela escola, fato que refletirá diretamente nos resultados escolares e nas futuras relações com o universo escolar.

Com base na teoria bourdieusiana, sabe-se existir uma cultura própria escolar que valoriza determinados conteúdos, saberes e comportamentos e desvalorizam outros, atuando também sobre a formação das identidades de gênero.

Por outro lado, conforme Bourdieu (2007), cada família transmite aos seus filhos uma cultura mais interna do que aparenta ser, além do ethos, sistemas de valores e costumes que são passados à sua prole- de maneira indireta e incessante, influenciando e determinando- quais serão as atitudes das crianças frente à escola e os mais variados sistemas e disposições, ou seja, é uma apropriação subjetiva de aquisição do êxito e fracasso escolar. 
OLIVEIRA, M. F. C.; MUZZETI, L. R.; MICHELETI, L. I. S. Sexualidade e educação sexual: uma perspectiva interdisciplinar na educação infantil . R. Científica UBM - Barra Mansa (RJ), ano XXVI,v. 23, n. 44, 1 .

Sem. 2021 p.90-102.

ISSN 1516-4071

\begin{abstract}
Essa relação natural com a cultura, ou seja, a proeza verbal e a competência cultural, só pode ser apropriada pelos agentes no interior de seu ambiente familiar, através da aprendizagem difusa, imperceptível, proporcionada pelas famílias pertencentes às classes cultas. Acrescenta ainda que, como essa familiaridade com a cultura é transmitida de maneira osmótica, até mesmo imperceptível no interior do contexto familiar, isto é, sem qualquer esforço metódico, ela não é percebida como tal e contribui para reforçar, nos agentes das classes cultas, a convicção de que eles devem os conhecimentos, atitudes e posturas que possuem aos seus dons, aptidões inatas ou vocações (MUZZETI, 2000, p. 257).
\end{abstract}

Segundo Bourdieu (2007), a herança cultural que cada um possui é o principal fator que interfere nas atitudes e visões da criança frente ao sistema de ensino e ao papel da escola, bem como no seu êxito e oportunidade de ascensão que esta pode representar.

Longe de afirmar que as estruturas de dominação são a-históricas, eu tentarei pelo contrário, comprovar que elas são produto de um trabalho incessante (e, como tal, histórico) de reprodução, para o qual contribuem agentes específicos (entre os quais os homens, com suas armas como a violência física e a violência simbólica) e instituições, famílias, Igreja, Escola, Estado (BOURDIEU, 1999, p. 46).

A falta de comunicação e preparo dos professores, gestores e agentes escolares em geral, no que diz respeito às questões relacionadas ao gênero e sexualidade, deve caminhar para uma tentativa de superação, investindo-se e estimulando-se o conhecimento e a instrução. A reciclagem e extensão da formação de um educador devem ser algo intrínseco à sua profissão e atuação, uma vez que a sociedade vive uma constante mudança, e os precursores e disseminadores de conhecimento e formação, em todos os seus sentidos, devem acompanhar esse movimento de trocas de necessidades para, assim, cumprir seu papel de orientador do desenvolvimento de seus alunos ou crianças e jovens em geral.

Outro fator importante para que tais medidas se façam legítimas é que a Lei de Diretrizes e Bases Curriculares - LDB (BRASIL, 1996), citada anteriormente, seja cumprida e que todos os alunos tenham seus diretos válidos, uma vez que já fora assegurado que o sistema educacional tem a obrigação de instituir e inspecionar os profissionais que devem possuir uma formação adequada para atuar em suas funções ou cargos.

Além disso, a formação dos educadores deve ser mais completa e os preconceitos e equívocos deixados de lado, principalmente dentro da Universidade, lugar onde opiniões são formadas e os conhecimentos apreendidos passados adiante para esses profissionais, visando sempre o benefício da comunidade.

Ao mesmo passo que programas são lançados e iniciativas mencionadas e encabeçadas a favor do ensino e orientação da sexualidade nas escolas, há uma força contrária por parte da 
OLIVEIRA, M. F. C.; MUZZETI, L. R.; MICHELETI, L. I. S. Sexualidade e educação sexual: uma perspectiva interdisciplinar na educação infantil . R. Científica UBM - Barra Mansa (RJ), ano XXVI,v. 23, n. 44,

1. Sem. 2021 p.90-102.

ISSN 1516-4071

sociedade e, muitas vezes, até de educadores, que- seja por questões políticas, receios ou preconceitos- atrapalham e atrasam o desenvolvimento e avanço do país.

Em 2004, através de uma iniciativa do Governo Federal, houve a criação do programa Brasil sem Homofobia (2004) cujo objetivo central era incentivar o combate à violência e à discriminação contra sujeitos cuja orientação sexual não era a heterossexual, bem como procuraram promover a cidadania homossexual. Uma das iniciativas desse programa era distribuir um conjunto de materiais que ficou conhecido como "Kit Escola Sem Homofobia", mas essa iniciativa foi suspensa, pois sofreu duras críticas e fortes reações de setores conservadores atrelados ao Governo. (GUIZZO; FELIPE, 2015, p. 6).

Outra medida tomada em relação às questões relacionadas ao gênero e sexualidade está o PNE/2001 - Plano Nacional de Educação, Lei 10.172/2001 que,

[...] estabelecia objetivos e metas a serem alcançados tanto nas diferentes etapas da Educação Básica, como no Ensino Superior. Nesse PNE foram trazidas importantes informações sobre a promoção de uma sociedade menos desigual no que diz respeito a gênero e sexualidade [...] Nos objetivos e metas para o Ensino Superior incluía-se a necessidade de se discutir nos cursos de formação de professores temas como gênero e educação sexual, articulados a noções de justiça e respeito mútuo. (GUIZZO; FELIPE, 2015, p. 4).

Ainda segundo Guizzo e Felipe (2015), o fim do PNE se deu em 2011 e essas medidas não foram ou foram pouco tomadas. Vale salientar também que atualmente o PNE foi “enxugado" para se tornar mais prático e as questões relacionadas ao gênero e sexualidade não foram sequer mencionadas.

No entanto, há uma dicotomia em relação à inclusão da Educação Sexual nas escolas uma vez que a temática está indicada no currículo, mas, é essencial que sejam dados subsídios aos profissionais da Educação para que eles possam ser capazes de orientar corretamente seus educandos. Dessa forma, ao mesmo passo em que há a necessidade da presença da Educação Sexual nas escolas, não se pode esquecer a importância de formar profissionais preparados e qualificados para lidar com tais temáticas.

Os horizontes da escola devem se ampliar cada vez mais, abrangendo conhecimentos sempre mais relevantes sobre adolescência e sexualidade, o que possibilitará o desenvolvimento de técnicas de abordagem ainda mais adequadas. Antes de mais nada, torna-se necessário buscar instrumentos que permitam melhor preparar aquele que vai orientar e, dentro desse enfoque, não só os professores de Ciências ou Biologia serão responsáveis pela transmissão do conteúdo, mas a escola como um todo. Esse conteúdo não mais contemplará a reprodução em detrimento da sexualidade. A educação sexual é, sim, um meio e não um fim, fazendo-se clara a necessidade de haver reflexão sobre as singularidades de cada faixa etária e sobre os fatores de risco (SAITO; LEAL, 2000, p. 45). 
OLIVEIRA, M. F. C.; MUZZETI, L. R.; MICHELETI, L. I. S. Sexualidade e educação sexual: uma perspectiva interdisciplinar na educação infantil . R. Científica UBM - Barra Mansa (RJ), ano XXVI,v. 23, n. 44, 1 .

Sem. 2021 p. $90-102$.

ISSN 1516-4071

\section{CONSIDERAÇÕES FINAIS}

Em linhas gerais, concluiu-se que a escola não vem tratando as questões relacionadas à sexualidade como devem, em especial no que diz respeito ao gênero, seja por falta de conhecimento, seja pela repressão e dominação masculina, cuja violência simbólica intrínseca a este comportamento está inculcada em nossa sociedade.

Dessa maneira, é imprescindível que a escola e a sociedade conscientizem-se de que a Educação sexual é algo que necessita de atenção e cuidados, sendo sua disseminação uma atitude urgente na busca pelo respeito às diversidades e singularidades culturais do país. Mais que promover uma instrução referente à sexualidade, propõe-se que as crianças, desde a mais tenra idade, possam ser capazes de conhecer o próprio corpo, além de respeitar incondicionalmente o outro. Somente assim, teremos uma sociedade igualitária, livre e autônoma em todos os seus tocantes.

A temática ainda é calcada em equívocos, possivelmente pela falta de importância a que se destina a tal, porém, muitas vezes a escola é chamada a responder e se responsabilizar por essa instrução. Por outro lado, e de acordo com o movimento da sociedade, a escola se omite e teme esta instrução que, muitas vezes, é vista como obrigação apenas da família.

Portanto, seguindo esse jogo de empurra-empurra, a educação sexual infantil fica à margem da sociedade, e perpetua a ignorância e desconhecimento por parte da escola e do âmbito familiar, prejudicando a todos, principalmente as crianças, que cada vez mais são expostas a essas questões sem um preparo ou instrução para lidar com tal.

Vale ressaltar ainda que, o silencio não desresponsabiliza nenhuma esfera, pelo contrário, o não falar sobre o assunto é uma maneira de educar e, sobretudo, de reforçar uma farsa a respeito da orientação sexual disseminada na sociedade através de valores morais.

Assim, a escola deve cumprir seu papel social de difundir a informação, mudando a sociedade, através da instrução e discussão em prol da integração e do proporcionando o prazer, cidadania e bem- estar.

A educação sexual deve superar o caráter terapêutico e médico, cuja instrução presente está calcada apenas na prevenção de doenças e gravidez indesejada, uma vez que, ambas as temáticas estão ligadas as relações sexuais, ou seja, ligadas ao sexo, equívoco proporcionado uma vez que este é uma expressão de sexualidade adequada à puberdade, negligenciadas todas as faixas etárias anteriores. 
OLIVEIRA, M. F. C.; MUZZETI, L. R.; MICHELETI, L. I. S. Sexualidade e educação sexual: uma perspectiva interdisciplinar na educação infantil . R. Científica UBM - Barra Mansa (RJ), ano XXVI,v. 23, n. 44,

1. Sem. 2021 p.90-102.

ISSN 1516-4071

Dessa maneira, a escola deve introduzir tais temáticas de maneira pedagógica, trazendo a importância de trabalhar a educação sexual pelo viés científico e, assim, autenticamente comprovado. Nesse sentido, escola e sociedade devem caminhar juntas, falando a mesma linguagem e defendendo os mesmos interesses em prol do desenvolvimento integral das crianças.

AGRADECIMENTOS: Coordenação de Aperfeiçoamento de Pessoal de Nível Superior Brasil (CAPES).

\section{REFERÊNCIAS}

BOURDIEU, P. A dominação masculina. Trad. Maria Helena Kühner. Rio de Janeiro: Bertrand Brasil, 1999.

BOURDIEU, P. Escritos de Educação. 9. ed. Petrópolis, RJ: Vozes, 2007. (Ciências sociais da educação)

BRASIL. Constituição da República Federativa do Brasil de 1988. Brasília: Planalto do Governo, 1988. Disponível em:

http://www.planalto.gov.br/ccivil_03/constituicao/constituicao.htm. Acesso em: 02 ago. 2020.

BRASIL. Lei no 8.069, de 13 de julho de 1990. Dispõe sobre o Estatuto da Criança e do Adolescente e dá outras providências. Diário Oficial da União: Seção 1, Brasília, DF, p. 13563, 16 jul. 1990.

BRASIL. MEC. SEESP. Política nacional de educação especial. Brasília: Ministério de Educação, 1994. Disponível em:

http://portal.mec.gov.br/index.php?option=com_docman\&view=download\&alias=16690politica-nacional-de-educacao-especial-na-perspectiva-da-educacao-inclusiva05122014\&Itemid=30192. Acesso em: 08 ago. 2020.

BRASIL. Lei n. 9394/96, de 20 de dezembro de 1996. Estabelece as diretrizes e bases da Educação Nacional. Diário Oficial da União: Seção 1, Brasília, DF: Ministério de Educação e Cultura, p. 27833, 23 dez. 1996.

BRASIL. Secretaria de Educação Fundamental. Parâmetros curriculares nacionais: introdução aos parâmetros curriculares nacionais. Brasília: MEC/SEF, 1997. 126 p. Disponível em http://portal.mec.gov.br/seb/arquivos/pdf/livro01.pdf. Acesso em: 8 ago. 2020.

FORMIGONI, B. M. S. Da idade média a idade moderna: um panorama geral da história social e da educação da criança. Temas em Educ. e Saúde, Araraquara, v. 6, n. 1, p. 137-150, 2010. Disponível em: https://periodicos.fclar.unesp.br/tes/article/view/9523. Acesso em: 8 set. 2020. 
OLIVEIRA, M. F. C.; MUZZETI, L. R.; MICHELETI, L. I. S. Sexualidade e educação sexual: uma perspectiva interdisciplinar na educação infantil . R. Científica UBM - Barra Mansa (RJ), ano XXVI,v. 23, n. 44, 1 .

Sem. 2021 p.90-102.

ISSN 1516-4071

GUIZZO, B. S.; FELIPE, J. Avanços e retrocessos em políticas públicas contemporâneas relacionadas a gênero e sexualidade: entrelaces com a Educação. In: REUNIÃO NACIONAL DA ANPED, 37., 2015, Florianópolis. Anais [...] Florianópolis: UFSC, 2015. Disponível em: www.anped.org.br/sites/default/files/trabalho-gt23-3858.pdf. Acesso em: 20 jul. 2020.

KRAMER, S.; NUNES, M. F. R.; CORSINO, P. Infância e crianças de 6 anos: desafios das transições na educação infantil e no ensino fundamental. Educação e Pesquisa, São Paulo, v. 37, n. 1, p. 69-85, jan./abr. 2011. DOI: http://dx.doi.org/10.1590/S15179702201100010000

LEÔNCIO, J. M. M. A orientação sexual nas escolas a partir dos parâmetros curriculares nacionais Educação, Gestão e Sociedade: revista da Faculdade Eça de Queirós, ano 3, n. 12, nov. de 2013. ISSN 2179-9636. Disponível em: www.faceq.edu.br/regs. Acesso em: 4 ago. 2019.

MONTEIRO, S. A. S.; STORTO, L. J. Educação infantil: uma reflexão plural da história e da sexualidade. RIAEE: Revista Ibero-Americana de Estudos em Educação, Araraquara, v. 14, n. 1, p. 237-252, jan./mar. 2019. Disponível em:

https://periodicos.fclar.unesp.br/iberoamericana/article/view/11865. Acesso em: 8 set. 2020.

MUZZETI, L. R. Escritos de educação. Educação \& Sociedade, v. 21, n. 73, 257-261.

Disponível em: https://www.scielo.br/scielo.php?script=sci_arttext\&pid=S0101-

73302000000400016. Acesso em: 5 ago. 2020.

ORTIZ, R. (Org.). Pierre Bourdieu, 1930 - Pierre Bourdieu: sociologia I. São Paulo:

Ática, 1983. (Grandes cientistas sociais; 39)

RIBEIRO, P. R. M. A institucionalização dos saberes acerca da sexualidade humana e da educação sexual no Brasil. In: FIGUEIRÓ, M. N. D. (Org.). Educação sexual: múltiplos temas, compromisso comum. Londrina: UEL, 2009. p. 129-140.

SAITO, M. I.; LEAL, M. M. Educação sexual na escola. Pediatria, v. 22, n. 1, p. 44-48, 2000 .

UNESCO. Orientações técnicas de educação em sexualidade para o cenário brasileiro: tópicos e objetivos de aprendizagem. Brasília: UNESCO, 2013. 53 p. Disponível em: http://www.unesco.org/new/fileadmin/MULTIMEDIA/FIELD/Brasilia/pdf/Orientacoes_educ acao_sexualidade_Brasil_preliminar_pt_2013.pdf. Acesso em: 8 set. 2020. 